\title{
HERBAGE QUALITY
}

\author{
A. T. JOHNS, Director, Plant Chemistry Division, D.S.I.R., \\ Palmerston North
}

The defining of the ideal balance of chemical compounds in the feed of ruminants, with their two-stage digestive system, is most difficult. We must consider not only the compounds as they exist in the plant itself, but also the products of their microbial fermentation in the animal's first two stomachs. A toxic substance may be detoxified or a harmless compound rendered harmful. The mineral balance may be altered in the animal and vitamins synthesised. The energy providing substances of the food are converted into an entirely different class of compounds in the rumen before being utilised by the animal. In this regard the physical state of the food may be as important as its chemical composition and the quality of the herbage may have to be defined in terms of the animal end product required.

The ideal pasture for ruminants has -been defined by Dr Melville as one that:

(1) Contains minerals and accessory food substances essential to animal health in sufficient quantity and in a state of balance within the feed.

(2) Does not contain harmful substances at a level which will cause animal disorders, a decline in production or fertility, or make the herbage unpalatable.

(3) Is capable of providing the protein and carbohydrate requirements of sheep and cattle.

We will consider some examples of each of these three categories of substances in turn.

1. A good example of how selection can vary the mineral content of varieties of pasture plants resulted from the work on iodine by $\mathrm{Dr}$ G. W. Butler and collaborators, in the D.S.I.R. It was demonstrated that the perennial ryegrass varieties studied had five times the level of iodine found in short-rotation ryegrass herbage. We know that a shortage of iodine in the diet results in goitre and so it could be expected that there would be a greater tendency for goitre on short-rotation ryegrass pastures than on perennial ryegrass. This has not proved to be the case, and it is obvious that factors other than the level of iodine in the plant must be taken into account. It is also apparent that the amount 
of a mineral, as determined by chemical analysis of the herbage, is by no means always a good guide to the amount available to the animal.

Another example of this nature is magnesium, a low level of which in the blood is known to be at least part of the cause of grass staggers or hypomagnesaemia in sheep and cattle. It is now recognised that the disease is not due to a simple deficiency of magnesium in the herbage, in spite of the fact that treatment with extra magnesium can alleviate the condition. Accounts of field investigations in which attempts have been made to relate pasture composition, herd management, and environmental conditions to the incidence of grass staggers continue to appear in profusion. Much work on the climatic and cultural factors influencing the magnesium content of herbage has been reported. It has been 'known for some time that high potassium fertilisation results in low magnesium uptake by herbage and possibly a lowered absorption of, magnesium from the alimentary tract of the animal. The most common conditions causing the ailment are cold wet weather and a high level of potassium and nitrogen in the herbage.

One of the most interesting developments in this field in recent years is the growing realisation that sodium may be an important factor in explaining the incidence of hypomagnesaemia in stock. It has been demonstrated in certain farm trials in the United Kingdom that the giving of common salt to herds can decrease the incidence of hypomagnesaemia. This finding is very interesting, as high potassium (besides lowering the amount of magnesium) can result in low sodium content in the herbage.

Studies in Holland on the water relationships in faeces have shown that the absorption of sodium. in the lower gut occurs against a considerable concentration gradient. It has been demon- strated that when the concentration of sodium falls that of magnesium rises, indicating lower absorption. Work by Ross in England has indicated that, with the isolated rat gut, an increase in sodium chloride content is associated with an increase in magnesium uptake. Ammonia and potassium chlorides are ineffective.

Though this work is only preliminary it does suggest that the low availability of magnesium from fertilised pasture may be primarily due to the low sodium content rather than a high potassium pre se. Further work is obviously urgently required and this example given in some detail illustrates how necessary it is to know what goes on in the animal once the herbage is digested if we are really to be able to define intelligently herbage quality from its chemical analysis. In addition to knowing the level of the individual elements we often have to take into account their relative concentrations. 
The levels of various mineral constituents are in the main influenced by the nutrient status in the soil, but for a particular soil the plant breeder, by selecting suitable varieties, can contribute to producing the best balance of mineral constituents if we know what that should be. Collaborative experiments by $\mathrm{Dr}$ Butler of Plant Chemistry Division and Dr P. C. Barclay of Grasslands Division have shown that there are differences between parent ryegrass plants which were maintained over a 12-month period. Up to threefold differences in level were found for sodium, calcium, manganese, aluminium, copper, titanium, iron, zinc sulphate, and acid-soluble phosphorus; no significant differences in potassium levels were observed.

We cannot, of course, consider ryegrass alone as, in New Zealand at any rate, we are dealing with a mixed sward containing both legumes and grasses. In many ways these two species are complementary in their mineral composition as is demonstrated in the following table.

TABLE I-COMPARISON OF THE MINERAL CONTENTS OF TRIFOLIUM REPENS AND LOLIUM PERENNE (12-YEAR AVERAGE)

\begin{tabular}{|c|c|c|c|c|c|c|c|c|c|}
\hline Treatment & & $\begin{array}{r}\mathrm{P}_{2} \\
\text { Clover }\end{array}$ & $\mathrm{O}_{5}$ & $\begin{array}{c}\text { Milli equ } \\
\text { Ca } \\
\text { Clover }\end{array}$ & $\begin{array}{l}\text { ivalents } \\
\text { Grass }\end{array}$ & $\begin{array}{r}\text { per } 10 \\
\mathbf{M} \\
\text { Clover }\end{array}$ & $\begin{array}{l}0 \mathrm{~g} \text { D.M } \\
\mathrm{gO} \\
\text { Grass }\end{array}$ & $\mathbf{K}_{2}$ & ${ }_{2} \mathrm{O}$ \\
\hline Control & & 35.3 & 31.7 & 86.4 & 30.3 & 21.2 & 14.6 & 26.7 & 32.8 \\
\hline N.P.K. & .... & 41.0 & 37.4 & 93.5 & 31.4 & 21.4 & 11.6 & 53.1 & 46.9 \\
\hline
\end{tabular}

The NPK treatment gave a threefold increase in yield of dry matter from clover and a twofold increase in the yield of the grass.

2. Plants that have been introduced and selected as being suitable food for ruminants are obviously not usually toxic to the animals that graze them. However, we are all well aware that there are seasonal metabolic diseases often linked with abnormal conditions for the growth of pasture plants. It is probable that most of the substances responsible for these upsets are normally present in the plants in amounts that the animal can cope with. Only when the particular plant becomes very dominant in the pasture or growth conditions induce a greatly enhanced synthesis of the offending substance do we strike trouble.

We well know that when, under favourable growth conditions, clover becomes dominant, bloat can be expected. Ryegrass dominance in the summer can lead to ryegrass staggers, a disease which appears to be due to some principle affecting the nervous system. 
We do not know the offending substances responsible for either of these two diseases and so at this stage cannot say that they can be eliminated by selecting particular varieties of legumes and grasses. Examples of substances that we do know something about are the oestrogens in clovers and the alkaloids and non-protein nitrogen substances in ryegrass.

The occurrence in clovers of substances capable of causing oestrus in animals has created considerable interest in recent years. The now classical case of serious outbreaks of infertility in sheep grazing on subterranean clover pastures in the 1940s in Australia was the first recorded example of ill health caused by the presence of natural oestrogens in animal foods. In New Zealand isolated instances of oestrogenic effects in sheep grazing on red cloverdominant pastures have been reported where the oestrogenic content of red clover has reached a level high enough to affect the reproductive capacity of grazing ewes. A considerable amount of work has been done at Plant Chemistry and Massey University College to identify the substances having oestrogenic properties.

From the use of synthetic substances with oestrogen activity, such as stilboestrol for influencing weight gains in cattle, it has become apparent that small amounts of oestrogens in forages may have beneficial effects on milk production and on carcass quality in cattle. Included among the pasture plants from which oestrogens have been isolated are subterranean clover, red clover, and the Ladino variety of white clover. The utilisation of the beneficial effects of oestrogens for the fattening animals would probably need to be confined to special pastures dominant in legumes, but the beneficial effect on weight gains and carcass composition would probably be offset by the necessity to combat bloat. However, the oestrogens are given as an example of substances that can be harmful or beneficial according to the type of animals grazing the pasture.

A considerable amount of work has been done on an alkaloid perloline, which occurs in ryegrass. As far as we know it has no harmful effects on animals but it is an example of the type of substance which could be responsible for certain disease problems. It has been found that there was a twentyfold difference in the perloline level among seven parent ryegrass plants used in a breeding programme. In a study of the effect of nitrogen fertilisation on perloline concentration, a twentyfold difference in perloline level was found in the same plants between low and high levels of nitrogen application, This is a good example of the extent of genetic and environmental factors that can influence 
the level of minor herbage constituents which could in some cases be very active pharmacologically.

A simple substance which can show marked fluctuations in levels in grasses is nitrate. Nitrate is reduced in the animal's rumen to ammonia and is utilised in the synthesis of protein. However, when excess nitrate is present, there can be an accumulation of nitrite, which is highly toxic to the animal. This nitrite accumulation is enhanced by a low soluble carbohydrate level in the herbage. Studies on ryegrass parent plants have shown up to a tenfold variation in nitrate concentration whereas fertility level and environmental conditions combined can lead to a very great fluctuation which can be quite violent.

Sub-lethal levels of nitrate have been suggested as being responsible for the autumn hogget ill-thrift of the North Island. The most obvious characteristic of the chemical composition of such herbage is the comparatively high content of non-protein compounds (particularly nitrate), coupled with a relatively low level of soluble carbohydrates. This leads to an "unbalanced" fermentation in the rumen of the grazing animal. There is also a considerable "unpalatability" apparent in such herbage and though nitrate per se does not appear to be the cause of ill-thrift, it is a good indicator of the unsatisfactory nature of the herbage.

There are again both genetic and environmental factors involved in determining the likelihood of the occurrence of high nitrate levels, with the less persistent varieties of ryegrass being more prone to unsatisfactory fluctuations in non-protein nitrogen levels. Clovers do not normally accumulate nitrate and can, by providing a supply of readily fermented carbohydrate, counteract the otherwise harmful effects of nitrate and other non-protein nitrogen constituents on the animal.

3. A deficiency of any of the dietary essentials, such as vitamins or minerals, or a toxicity, usually leads to a well recognised clinical syndrome, and much research in nutritional and veterinary science has been concerned with these. By contrast, a shortage of total energy supply from a diet adequate in dietary essentials does not lead to an easily recognised condition. There may be an insidious reduction in growth and reproductive and lactation performance. It is now recognised that such a shortage of energy is a much more general cause of diminished animal productivity than the factors listed in the previous two sections.

Work in the United Kingdom and the U.S.A. has in recent years led to a much better understanding of the factors determining the nutritive value of various feeds for livestock and the limitations they place on livestock production. It is clear from the work of 
Blaxter and his associates that quite small changes in the digestibility of food can have considerable consequences in live-weight gain through its effect on changes in the rate of passage of food through the digestive system and the proportion of volatile acid produced in, and absorbed from, the rumen. According to Blaxter the intake of food by ruminants is directly correlated with the digestible energy the food contains. The better the food is the more the animal eats, with no adjustment of food intake to its energy demands. This is a direct contrast to the situation in nonruminants.

A second important factor is that the proportion of end products from the more readily fermented food differs from that obtained with more fibrous herbage. Forage with a high fibre content produces a high proportion of acetic acid in the rumen whereas that containing a greater fraction of its carbohydrate in soluble form gives relatively less acetic acid and more of the other end products of fermentation, i.e., propionic and butyric acids. These are utilised by the animal equally well for its maintenance requirements, but above maintenance, as a source of energy for fattening, the energy of acetic acid is used with an efficiency of 33 per cent, propionic with an efficiency of 55 per cent, and butyric with an efficiency of 62 per cent.

It can be seen from these considerations that the ruminant not only eats more of the more readily digestible food, but also assimilates better the energy that the food contains, owing to the production of more of the more efficiently utilised fermentation products.

These effects have been demonstrated in a trial in which liveweight gains in sheep have been determined in animals grazing perennial ryegrass, short-rotation ryegrass, and mixtures of each with white clover.

After 18 months' grazing the animals fed short-rotation ryegrass were on average some $23 \mathrm{lb}$ heavier than those fed on perennial ryegrass; the addition of clover to the grass resulted in an increase of $28 \mathrm{lb}$ over perennial ryegrass alone, and $17 \mathrm{lb}$ over shortrotation ryegrass alone. Thus the animals fed short-rotation ryegrass and clover were some $40 \mathrm{lb}$ heavier than those on perennial grass. The average daily weight gains of lambs were: on perennial ryegrass, $0.30 \mathrm{lb}$; on perennial ryegrass + white clover, $0.40 \mathrm{lb}$; on short-rotation ryegrass, $0.38 \mathrm{lb}$; and on short-rotation ryegrass + white clover, $0.47 \mathrm{lb}$.

From subsequent work carried out at Plant Chemistry Division by Dr Bailey there appears to be little doubt that these differences are due to (a) the higher level of soluble sugars and lower fibre 
content of the short-rotation ryegrass compared with perennial ryegrass and (b) the high proportion of soluble carbohydrates in clover. There was little difference in the protein content of the $\mathrm{p}$ a s t u res.

The increase in live weight is accounted for by an increase in both protein and fat. It is desirable to increase protein without fat to give us a lean carcass, but we do not know how to achieve such a desirable product at this stage.

The same criteria of herbage quality as have been found for achieving a high rate of weight gain do not necessarily apply for other animal products. For instance, if the rations for dairy cows become too low in fibre, milk-fat production is depressed, and with this is associated a marked change in the molar proportions of volatile fatty acids in the rumen; that is, a lowering of the amount of acetic acid and a rise in propionic and butyric acids.

Both acetate and butyrate are precursors of the fatty acids of milk fat up to and including those with 16 carbon atoms. The infusion of either acetate or butyrate into the rumen is effective in reversing a depression of milk fat caused by a low fibre diet. Conversely, the constant infusion of propionic acid into the gut of normal cows causes a marked fall in fat content of the milk and a rise in its protein content. Depressions of milk fat can be detected when the molar proportion of propionic acid in the rumen liquor rises to 25 per cent and are severe at molar proportions of more than 30 per cent. It appears likely that -when the fat content of milk is depressed as the proportion of propionic acid in the products of digestion rises, a rise occurs in the deposition of body fat.

That a particular feed which is ideal for fattening is not necessarily suitable for milk production was well illustrated by experiments carried out by Shaw and his associates in the U.S.A. On a ration of luceme hay, maize, and linseed meal steers gained $2.00 \mathrm{lb}$ per day while milking cows yielded milk of normal fat percentage ( 3.6 per cent). When steers were fed the same basic diet, but with the hay ground and made into pellets and the maize cooked (giving a high proportion of propionic acid) steers gained $2.44 \mathrm{lb}$ per day, but the cows' milk fat percentage dropped to 1.4 per cent. It is thus necessary for us in the ultimate to define herbage quality in terms of the end product desired.

In this paper a few aspects of herbage quality have been considered. If the paper has done nothing else, it is hoped it has made obvious the great complexity of the problem of providing the ideal food for ruminants. In countries where concentrate feeding is used it is somewhat simpler for the findings of research to be put into 
practice by altering the composition of the ration. In the case of grazing animals properties, other than chemical composition of pasture must be considered, for example, their seasonal production, their susceptibility to pests and diseases, their persistence in the sward and, of course, the fact that their chemical composition varies with stage of growth and environment.

Many of the defects of pasture are peculiar to either grasses or clovers and often manifest themselves only when either one becomes markedly dominant in the pasture. In many aspects grasses and clovers are complementary in their chemical composition and, at the present state of our knowledge, the maintenance of a well balanced legume-grass sward would seem to be the immediate aim of the farmer to avoid as far as possible the metabolic diseases that are some of the perils he faces in achieving increased production.

\section{DISCUSSION}

Q. Have you carried out any trials with long rotation ryegrass to determine its fattening qualities for lambs and hoggets?

A. Yes. We have found that it produces weight gains intermediate between those obtained on short rotation and perennial ryegrass.

Q. Would the difference obtained in liveweight gains of sheep apply to dairy production also?

A. We are carrying out trials with dairy cows but would not expect very marked differences in milk or fat production.

Q. Have you carried out trials with a more complex pasture such as ryegrass, timothy and clover?

A. No. In order to relate weight gains in animals to the chemical composition of the pasture, we need to be able to sample what the animal is eating. This can only be done with certainty with pure stands of species or at the most with a sample mixture such as ryegrass and clover.

Q. As potassium is antagonistic to magnesium in its uptake by the plant, what is going to be the result of farmers using $\frac{1}{2}$ ton of SO-50 mixture of potassium-superphosphate per acre?

A. Where there is a deficiency of potassium, it has to be rectified to obtain maximum pasture growth. Where this applies there should be an increase in clover production which contains more magnesium than. do the grasses so that in rectifying potassium deficiency we would not necessarily decrease the amount of magnesium available to the animal. 